\title{
Clinical utility of testing AQP4-IgG in CSF
}

\section{Guidance for physicians}

\section{OPEN}

Masoud Majed, MD*

James P. Fryer, MS*

Andrew McKeon, MD

Vanda A. Lennon, MD,

$\mathrm{PhD}$

Sean J. Pittock, MD

Correspondence to

Dr. Pittock:

pittock.sean@mayo.edu

\section{ABSTRACT}

Objective: To define, using assays of optimized sensitivity and specificity, the most informative specimen type for aquaporin-4 immunoglobulin G (AQP4-lgG) detection.

Methods: Results were reviewed from longitudinal service testing for AQP4-IgG among specimens submitted to the Mayo Clinic Neuroimmunology Laboratory from 101,065 individual patients. Paired samples of serum/CSF were tested from 616 patients, using M1-AQP4transfected cell-based assays (both fixed AQP4-CBA Euroimmun kit [commercial CBA] and live in-house flow cytometry [FACS]). Sensitivities were compared for 58 time-matched paired specimens (drawn $\leq 30$ days apart) from patients with neuromyelitis optica (NMO) or high-risk patients.

Results: The frequency of CSF submission as sole initial specimen was 1 in 50 in 2007 and 1 in 5 in 2015. In no case among 616 paired specimens was CSF positive and serum negative. In 58 time-matched paired specimens, AQP4-lgG was detected by FACS or by commercial CBA more sensitively in serum than in CSF (respectively, $p=0.06$ and $p<0.001$ ). A serum titer $>1: 100$ predicted CSF positivity $(p<0.001)$. The probability of CSF positivity was greater around attack time ( $p=0.03$ ). No control specimen from 128 neurologic patients was positive by either assay.

Conclusions: FACS and commercial CBA detection of AQP4-lgG is less sensitive in CSF than in serum. The data suggest that most AQP4-lgG is produced in peripheral lymphoid tissues and that a critical serum/CSF gradient is required for IgG to penetrate the CNS in pathogenic quantity. Serum is the optimal and most cost-effective specimen for AQP4-IgG testing.

Classification of evidence: This study provides Class IV evidence that for patients with NMO or NMOSD, CSF is less sensitive than serum for detection of AQP4-IgG. Neurol Neuroimmunol Neuroinflamm 2016;3:e231; doi: 10.1212/NXI.0000000000000231

\section{GLOSSARY}

AQP4 = aquaporin-4; $\mathbf{C B A}=$ cell-based assay; FACS $=$ fluorescence-activated cell sorting; HR-NMO = high risk for neuromyelitis optica; IgG = immunoglobulin G; IRB = Institutional Review Board; $\mathbf{M S}=$ multiple sclerosis; $\mathbf{N M D A R}=$ NMDA receptor; NMO = neuromyelitis optica; NMOSD = neuromyelitis optica spectrum disorder.

Neuromyelitis optica (NMO) is a severe, usually idiopathic, relapsing inflammatory demyelinating disease of the CNS that preferentially affects the optic nerve, spinal cord, and circumventricular organ systems. ${ }^{1-3}$ The most commonly ordered antibody test in multiple sclerosis (MS) clinics is for aquaporin-4 immunoglobulin G (AQP4-IgG), an NMO spectrum-restricted autoantibody that targets the astrocytic AQP4 water channel. Detection of AQP4-IgG positivity aids differentiation of NMO from MS, predicts relapses, and justifies initiation of immunosuppressive rather than immunomodulatory therapy. ${ }^{1-4}$

Fluorescent cell-based assays (CBA), both observer-scored and quantitated by fluorescenceactivated cell sorting (FACS), have highest sensitivity and specificity for detecting AQP4-IgG in serum. ${ }^{5,6}$

\footnotetext{
*These authors contributed equally to this work.

From the Departments of Laboratory Medicine and Pathology (M.M., J.P.F., A.M., V.A.L., S.J.P.), Neurology (A.M., V.A.L., S.J.P.), and Immunology (V.A.L.), Mayo Clinic, Rochester, MN.

Funding information and disclosures are provided at the end of the article. Go to Neurology.org/nn for full disclosure forms. The Article Processing Charge was paid by NIH.

This is an open access article distributed under the terms of the Creative Commons Attribution-NonCommercial-NoDerivatives License 4.0 (CC BY-NC-ND), which permits downloading and sharing the work provided it is properly cited. The work cannot be changed in any way or used commercially.
} 
There have been several reports ${ }^{7,8}$ (using CBAs) that serum is generally a more sensitive specimen for AQP4-IgG detection than CSF. Those reports were based on small numbers of patients, most lacking paired serum/CSF specimens, and did not include FACS analyses. ${ }^{7-10}$ In the course of testing 124,315 patient samples for AQP4-IgG on a clinical service basis, we were surprised to note over successive years an increasing number of singular CSF samples being submitted to the Mayo Neuroimmunology Laboratory for AQP4-IgG testing. We therefore performed a longitudinal audit of specimen types submitted for AQP4-IgG testing since 2007. In order to define the optimal specimen type for AQP4-IgG detection, we systematically analyzed results for paired serum and CSF samples submitted from $\mathrm{NMO} /$ high-risk cases.

METHODS Patients and specimens. Over a 9-year period, the Mayo Clinic Neuroimmunology Laboratory screened 101,065 patients for AQP4-IgG (124,315 specimens, serum or CSF). We determined the initial specimen type on an annual basis. From a database of 533 Mayo Clinic cases of NMO/ NMO spectrum disorder (NMOSD) (78\% AQP4-IgGseropositive), we identified 58 cases with serum and CSF specimens drawn within 30 days of each other (time-matched paired specimens) who were classified clinically as having NMO (Wingerchuk criteria) ${ }^{2}$ or a high risk for NMO (HR$\mathrm{NMO}$, defined as longitudinally extensive transverse myelitis [ $>3$ vertebral segments; monophasic or recurrent] or recurrent optic neuritis). Samples (stored at $-80^{\circ} \mathrm{C}$ ) were tested by cellbased assays utilizing M1-AQP4-transfected HEK293 cells (both fixed [commercial AQP4-CBA kit; Euroimmun, Lubeck, Germany] and live [in-house AQP4-FACS assay]). Disease activity at the time of specimen draw was defined as preattack (drawn within 30 days preceding an attack), attack (drawn within 30 days after attack onset), attack/remission bridge (drawn 31-90 days after attack onset), or remission (drawn $>90$ days after attack onset).

To validate results for these time-matched paired specimens of Mayo Clinic patients, we also analyzed commercial CBA data for 552 non-Mayo Clinic patients whose paired serum/CSF specimens (time-matched or non-time-matched) had been submitted to Mayo Medical Laboratories for testing without clinical data. In addition, we retested by FACS assay stored time-matched paired specimens from 6 patients that by first generation tissuebased indirect immunofluorescence assay had yielded negative serum results for NMO-IgG and positive CSF results. Those patients were the subject of a report that CSF testing may be informative when serum is negative. ${ }^{11}$ In total, we evaluated 616 paired (time-matched or non-time-matched) serum and CSF. We also tested by commercial CBA paired (time-matched or non-time-matched) serum/CSF samples from 128 control neurologic patients (36 had MS).

Assays. We employed FACS and commercial CBA protocols that are highly sensitive (FACS $83 \%$ and commercial CBA $75 \%$ for serum), $100 \%$ specific, and standardized for detecting
AQP4-IgG in a clinical setting. ${ }^{5}$ For CBA, specimens were tested at 1/10 dilution (serum) and nondiluted (CSF) without further titration. For FACS assay, serum was screened at $1 / 5$ dilution and, if positive, retested at 1/10 dilution and titrated further in 10-fold dilution steps. CSF was screened at $1 / 2$ dilution and, if positive, titrated in doubling dilutions. The farthest dilution yielding a positive result was recorded as the endpoint of positivity.

Data from 10 time-matched paired serum-CSF specimens were available to calculate the AQP4-IgG index for serum vs CSF ([CSF/serum AQP4-IgG titer]/[CSF/serum total IgG level]). ${ }^{12}$ Indices exceeding 4 are considered supportive of intrathecal antibody synthesis. ${ }^{12}$ Commercial CBA results were reported as positive or negative. ${ }^{5}$

Statistical methodology. The study's primary aim was to define the optimal specimen type for AQP4-IgG detection (Class IV evidence). McNemar test was used to determine interassay agreements. Clinical data were compared by MannWhitney $U$ test, Kruskal-Wallis test, or Fisher exact test. Spearman nonparametric test was used for correlation analysis. All analyses employed IBM SPSS software (release 20.0, IBM, SPSS Inc., Chicago, IL). $p$ Values less than 0.05 were considered statistically significant.

Standard protocol approvals, registrations, and patient consents. The study was approved by the Mayo Institutional Review Board (IRB 08-007846 and IRB 08-006647).

RESULTS In 9 years, the frequency of CSF submission as initial test specimen for assaying AQP4-IgG increased 10-fold. Figure 1 illustrates the annual trend of specimen types submitted to the Mayo Neuroimmunology Laboratory for AQP4-IgG testing. In 2007, the frequency of CSF submission as sole initial specimen was 1 in 50. In 2015, it was 1 in 5 .

For matched specimens, AQP4-IgG was detected more sensitively in serum than in CSF. Figure 2 illustrates the detection rates for AQP4-IgG in serum compared with CSF (by both FACS and commercial CBA). In no case did CSF but not serum yield a positive result among 58 cases of $\mathrm{NMO}$ or HR-NMO for whom time-matched paired specimens were tested. AQP4-IgG was detected more sensitively in serum than in CSF by both FACS assay $(p=0.06)$ and by commercial CBA $(p<0.001)$. However, AQP4IgG was detected more sensitively in CSF by FACS than by commercial CBA ( $p=0.008)$. We validated these results in a separate cohort of 552 paired serum/ CSF specimens (time-matched and non-timematched) submitted through Mayo Medical Laboratories from patients without clinical information. Again, in no case was a CSF specimen found to be positive when the serum specimen was negative. By commercial CBA, both CSF and serum were positive for 2 of the 552 paired specimens tested; only serum was positive for another 2 paired specimens. All of the remaining 548 pairs were negative. We took the opportunity to retest by FACS assay serum specimens stored from 6 patients whose CSF was earlier scored positive while the 


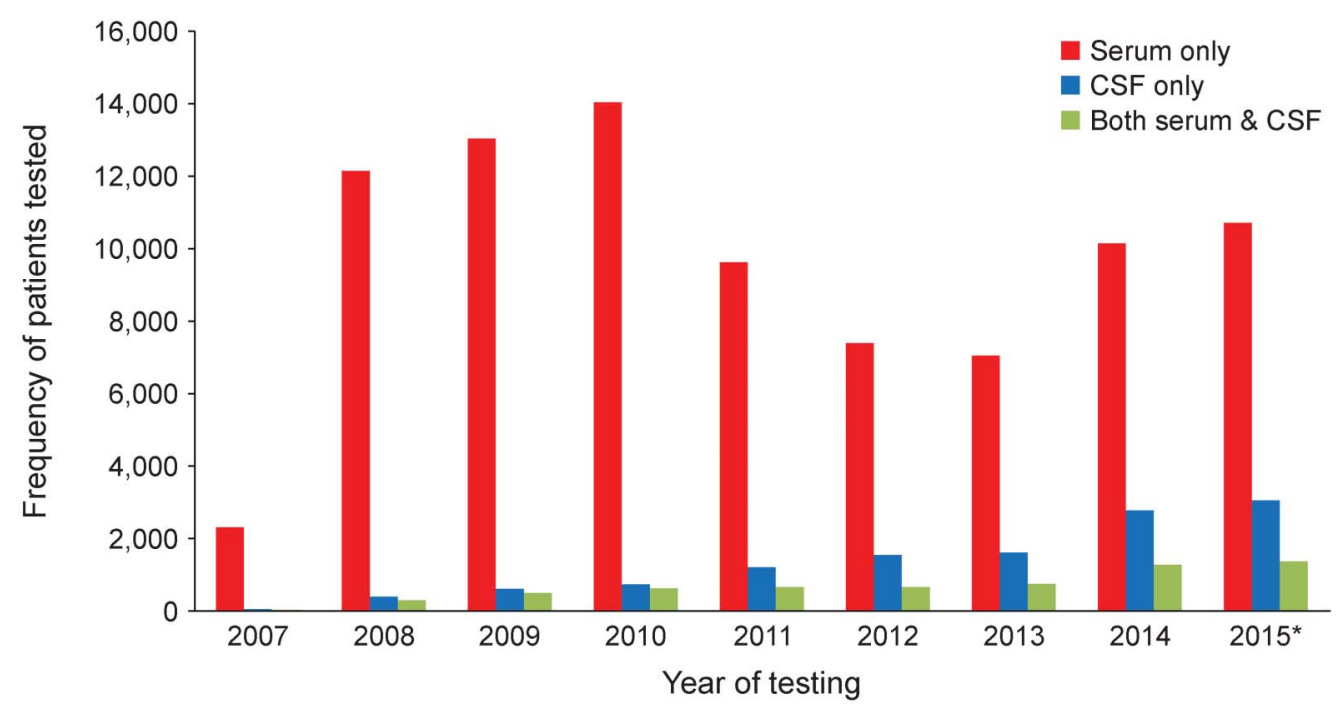

\begin{tabular}{|l|l|l|l|l|l|l|l|l|l|}
\hline $\begin{array}{l}\text { CSF as the only } \\
\text { specimen type } \\
\text { submitted; } \% \\
\text { of total samples }\end{array}$ & 2.37 & 3.15 & 4.87 & 4.80 & 10.54 & 16.13 & 17.15 & 19.55 & 20.18 \\
\hline
\end{tabular}

*Expected values based on number of samples tested by September 15, 2015.

matched sera were scored negative. ${ }^{11}$ In contrast to the earlier report (when tested by the far less sensitive first-generation [tissue-based] immunofluorescence assay), those stored serum specimens all yielded positive results by FACS assay. No specimen from 128 control neurologic patients was AQP4-IgGpositive by either FACS or commercial CBA.

Of 11,143 CSF specimens submitted singularly for initial AQP4-IgG testing since 2007, only 291 were positive $(2.6 \%)$. Given the significantly greater sensitivity of serum testing, it is concerning that serum was subsequently submitted from only 688 of the 10,852 patients whose CSF specimen had yielded a negative result; $4 \%$ of those sera yielded a positive result. The median delay from draw date of CSF to serum was 133 days.

Serum and CSF titers correlate significantly. Serum AQP4-IgG titers (reciprocal of last dilution positive) were significantly higher than CSF titers $(p<0.001)$. For time-matched paired specimens, median serum titer was significantly lower when CSF was negative than when CSF was positive (respective median serum titers 10 vs 10,000 ; $p<$ 0.001). Figure $3 \mathrm{~A}$ illustrates the significant correlation of serum and CSF titers (Spearman $r=$ 0.499; $p=0.030$ ).

A serum titer exceeding 100 predicted CSF positivity and a serum titer less than 100 predicted CSF negativity. Of 3 pairs with serum titer $=100$, matched CSF was positive in 1 and negative in the other 2 .
Figure 3B illustrates higher serum AQP4-IgG titers around attack time than at other times $(p=$ 0.012). Higher serum titers around attack time and correlation of serum and CSF titers may explain why AQP4-IgG detection was more likely in CSF around attack time $(p=0.03)$.

$A Q P 4-I g G$ index as an indicator of intrathecal AQP4-IgG synthesis. The index was below 1 in all remission/ bridge pairs and in 2 of the attack/preattack pairs (figure 4). In one attack pair, the index was 4.6 (slightly above the cutoff of 4). Commencement of dexamethasone treatment ( $4 \mathrm{mg}$ QID) 3 days before the draw date of those specimens may have caused a more robust decrease in AQP4-IgG in serum than in CSF.

DISCUSSION This study, the first to validate a FACS assay for detecting AQP4-IgG in CSF, reveals that serum is more informative than CSF for detecting AQP4-IgG in patients with NMOSD, provided that assays are standardized and sensitive. The findings suggest that testing CSF for AQP4-IgG does not provide any additional benefit if serum testing yields a negative result.

We suspect that the changed pattern for ordering AQP4-IgG testing in the past 8 years (a 10-fold increase in requests for CSF rather than serum testing) reflects neurologists' increasing awareness of the entity of autoimmune NMDA receptor (NMDAR) encephalitis. CSF is the recommended initial test 
Figure 2 Concordance of results for commercial cell-based assay (CBA) and fluorescence-activated cell sorting (FACS) assays, FACS titers, and disease activity at draw date in time-matched paired specimens of serum and CSF from patients with neuromyelitis optica (NMO) and high-risk (HR) NMO (figure 3B plots serum endpoint vs CSF endpoint in these time-matched paired samples)

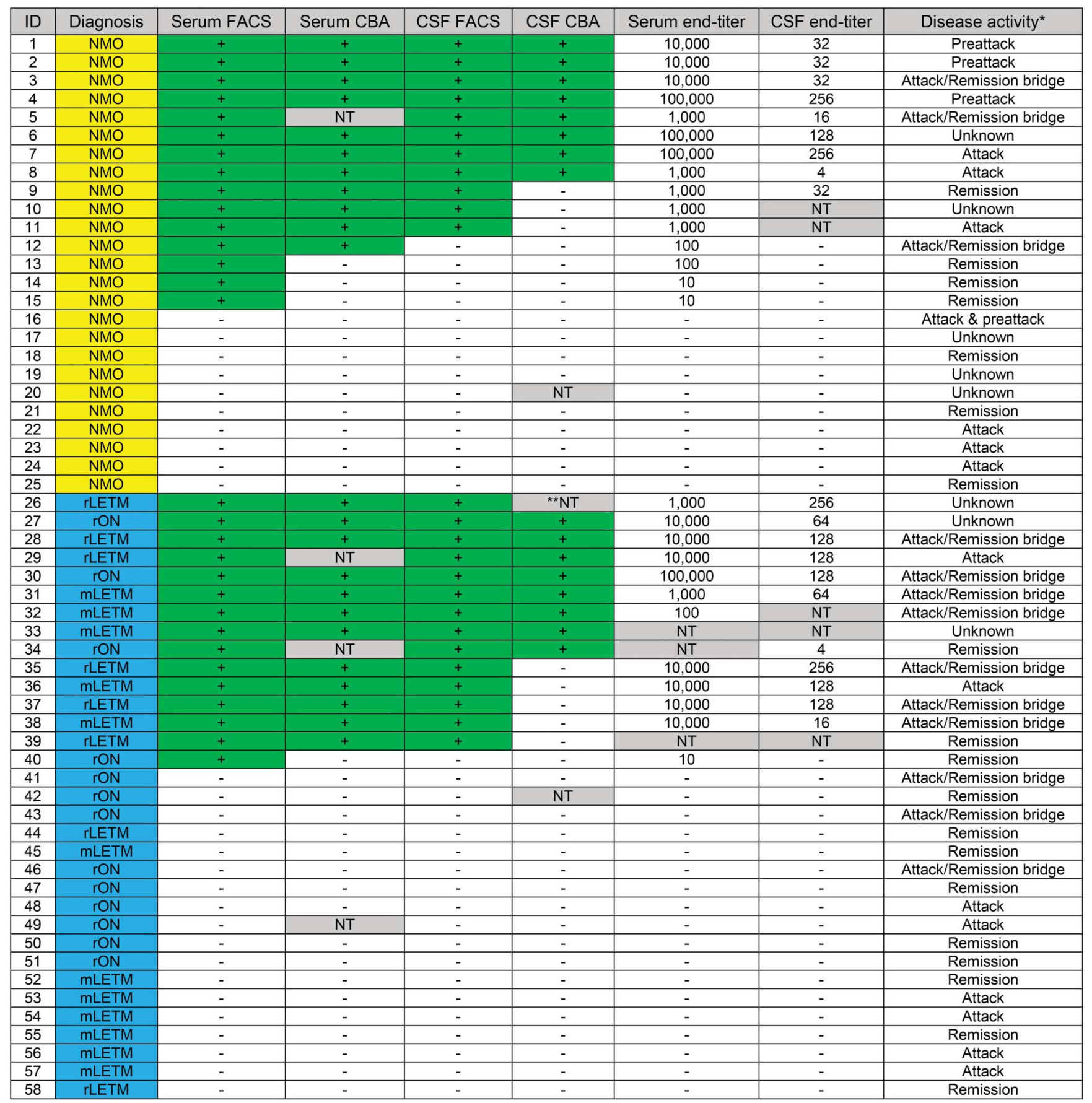

Positive samples are marked with a green background. Samples not tested (NT) are marked with a gray background. Patients with NMO are highlighted in yellow; HR-NMO patients in blue. $\mathrm{mLETM}=$ monophasic longitudinally extensive transverse myelitis; rLETM = recurrent longitudinally extensive transverse myelitis; $\mathrm{rON}=$ recurrent optic neuritis.

specimen for that syndrome because it is wellestablished as more sensitive and specific than testing serum. ${ }^{13}$ In a recent study of 250 patients with autoimmune NMDAR encephalitis, NMDAR-IgG was detected in CSF of 36 patients (15\%) whose matched serum was negative. ${ }^{13}$ The imperative to inform neurologists of the importance of submitting CSF for
NMDAR-IgG testing in cases of suspected encephalitis appears to have resulted in inappropriate extrapolation of that guideline to other inflammatory CNS disorders where serum may in fact be the more informative specimen type to test. It is also possible that many singular CSF specimens were submitted to the Mayo Clinic Neuroimmunology Laboratory for 


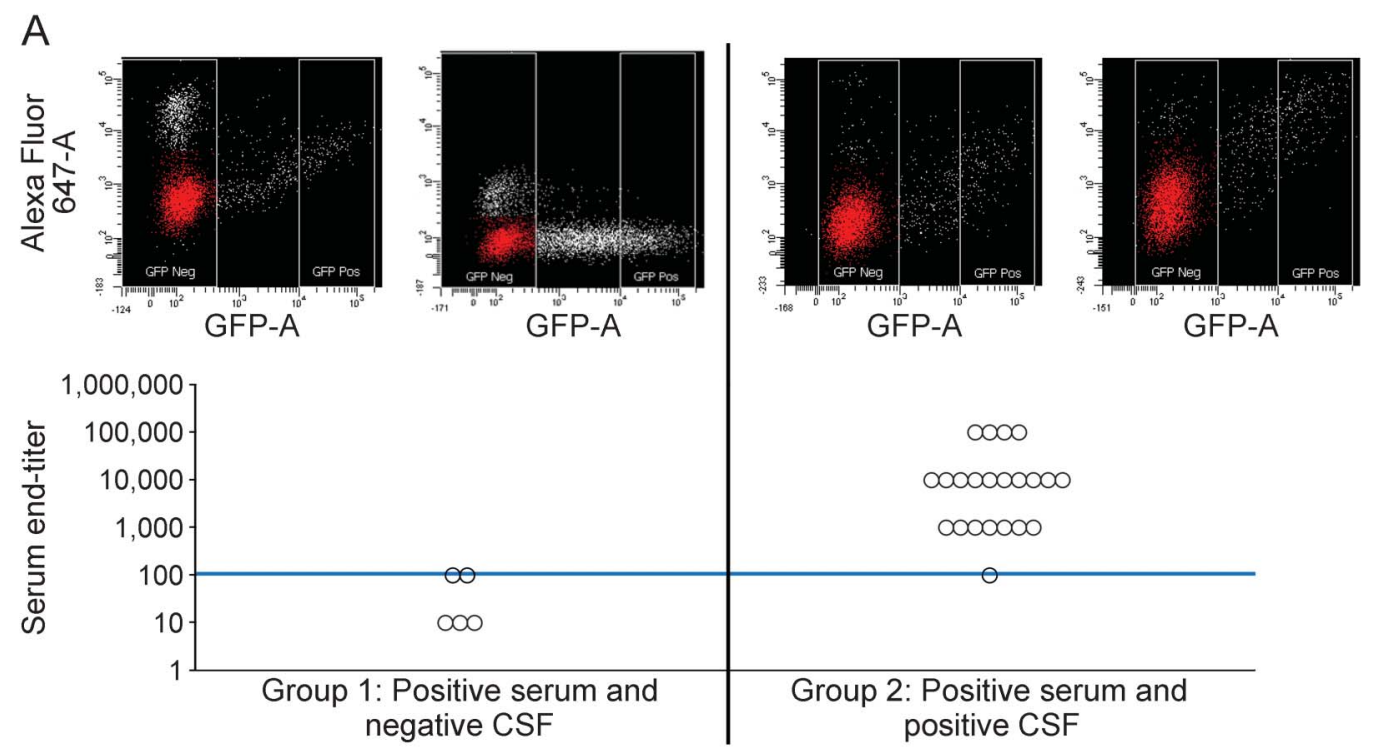

B

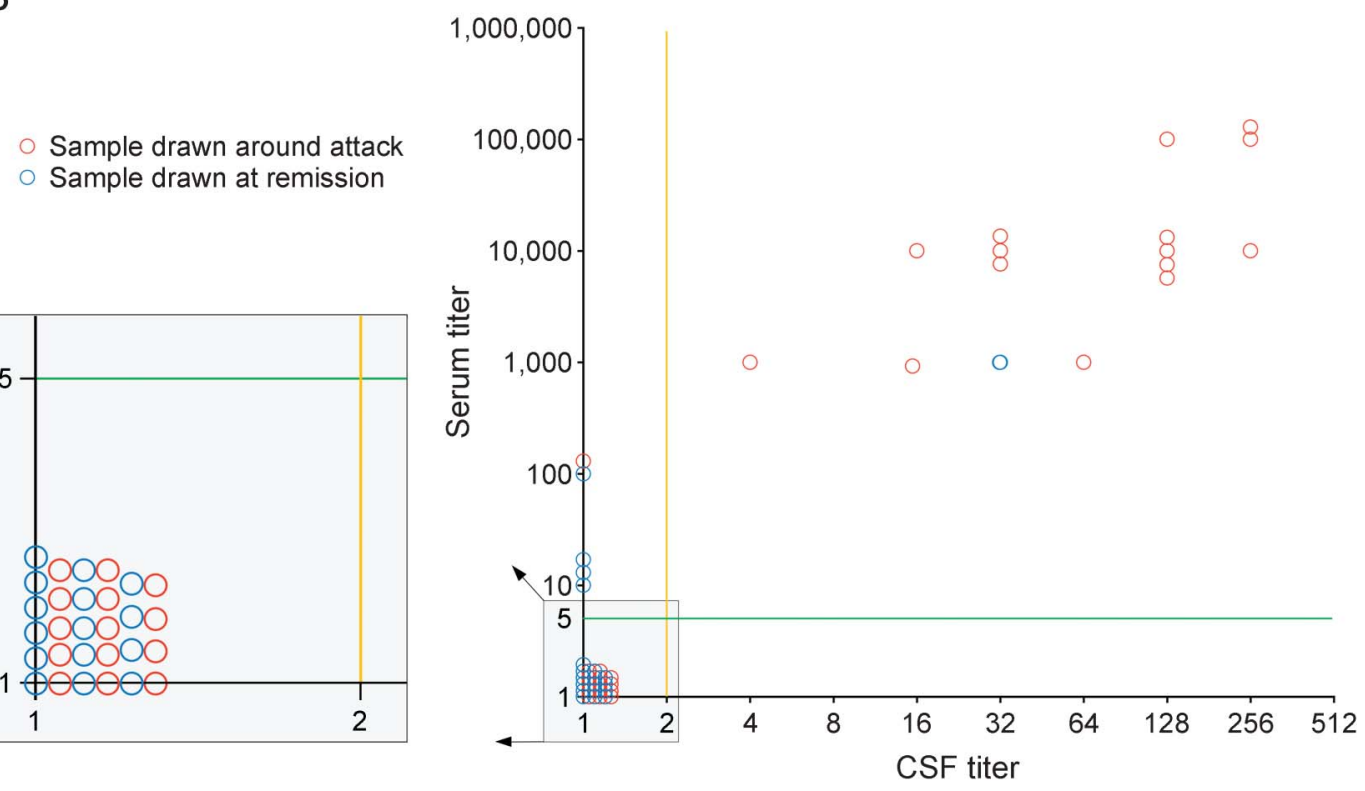

(A) Aquaporin-4 immunoglobulin G titer of serum samples stratified by time-matched paired CSF sample serostatus. Group 1: Serum is positive but the paired CSF is negative. Group 2: Both serum and CSF are positive. FACS results for serum and CSF samples are shown for patient 15 (group 1) and patient 36 (group 2). DIVA software is used to determine the median fluorescent values of the AlexaFluor 647 signal for both the GFP-negative and positive populations. The main GFP-negative population (illustrated in red) is determined using a histogram with AlexaFluor 647 signal ( $x$-axis) vs counts (y-axis) and a snap-to-interval gate within the software that distinguishes the main GFP-negative population. The blue line shows that the serum titer $>1: 100$ predicted CSF positivity. (B) Comparing serum and CSF end titer in samples drawn around an attack (preattack, attack, and attack/remission bridge) with those drawn during remission. Samples left to the orange solid lines are negative in CSF. Samples below the green solid lines are negative in serum.

AQP4-IgG testing in response to a negative report for serum tested by less sensitive ELISA assay in another laboratory. ${ }^{5}$

In none of our study's cases did CSF yield a positive result when serum yielded a negative result (by either commercial CBA or FACS assay). Also, consistent with prior reports, ${ }^{7,8,10}$ in no case was any specimen positive by commercial CBA but negative by FACS. The demonstrated superior sensitivity of
FACS for detecting AQP4-IgG supports its use as the optimal tool for AQP4-IgG detection in both serum and CSF.

The identification of AQP4-IgG in archival serum specimens from 6 cases previously reported positive only in CSF (when tested by less sensitive tissuebased immunofluorescence $)^{6}$ further supports our contention that CSF offers no additional information with respect to a patient's AQP4-IgG status when 
Figure 4 Aquaporin-4 immunoglobulin G (AQP4IgG) index in time-matched paired serum-CSF specimens: 3 attack $/$ preattack pairs and 7 bridge/remission pairs

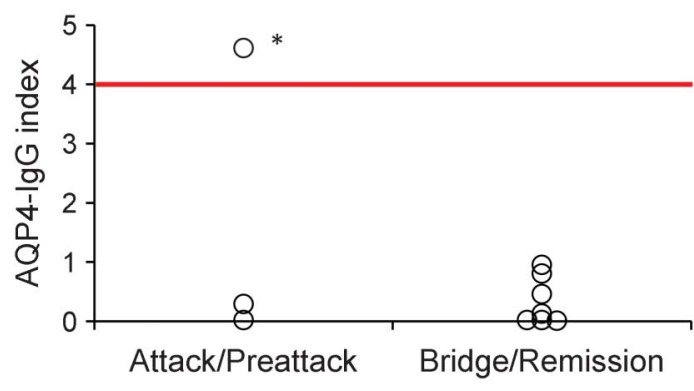

Red line indicates the cutoff of 4 for intrathecal AQP-IgG synthesis. *This patient was being treated with dexamethasone (4 mg QID) starting 3 days before date of sample draw, which may have caused a more robust decrease in AQP4-IgG in serum compared with CSF.

assays of optimal sensitivity and specificity are used in the diagnostic evaluation. ${ }^{11}$ Because CSF generally lacks or has lower levels of the interfering non-organspecific autoantibodies that are common in serum of patients with NMOSD, CSF does offer an advantage over serum as test specimen for NMO-IgG by tissuebased immunohistochemical assays in geographic regions lacking access to molecular-based assays. ${ }^{11}$

The relatively low sensitivities (60\% and $48 \%$ ) for FACS and commercial CBA in our time-matched paired CSF/serum specimens are likely explained by selection bias. This study cohort was enriched for seronegative cases for whom negative serum testing prompted CSF referral. In a large study with unbiased samples, FACS and commercial CBA sensitivity of detection of AQP4-IgG in serum was $83 \%$ and $75 \%$, respectively. ${ }^{5}$

The significantly higher titer of AQP4-IgG in serum compared with CSF and the very low AQP4$\mathrm{IgG}$ index in 9 of the 10 tested paired samples is consistent with the notion that most AQP4-IgG is produced in peripheral lymphoid tissues rather than intrathecally, and that a critical serum to CSF gradient is required for $\operatorname{IgG}$ to penetrate the CNS in pathogenic quantity. ${ }^{7,8,10}$ Similar to reports from other studies, serum AQP4-IgG titers were higher around attack time. This plausibly explains why antibody detection in CSF was more frequent at that time.

\section{AUTHOR CONTRIBUTIONS}

Study concept and design: Dr. Majed, J.P. Fryer, Dr. McKeon, Dr. Pittock. Acquisition, analysis, or interpretation of data: all authors. Drafting of the manuscript: Dr. Majed, J.P. Fryer, Dr. Pittock. Critical revision of the manuscript for important intellectual content: all authors. Statistical analysis: Dr. Majed. Obtained funding: Dr. Pittock. Study supervision: Dr. Pittock.

\section{STUDY FUNDING}

Funding provided by the Guthy-Jackson Charitable Foundation and the NIH (NS065829).

\section{DISCLOSURE}

M. Majed and J. Fryer reports no disclosures. A. McKeon received research support from Medimmune, Inc. V.A. Lennon receives royalties from RSR/Kronus for sale of aquaporin- 4 autoantibody testing kits and for commercial aquaporin- 4 autoantibody testing performed outside Mayo Clinic, received research support from NIH, received license fee payments for RSR/Kronus for sale of aquaporin- 4 autoantibody testing kits, non-Mayo sites performing "home brew" diagnostic testing for aquaporin-4 autoantibody, and has a potential financial interest in "Aquaporin-4 as an aid for cancer diagnosis." S.J. Pittock consulted for Alexion Pharmaceuticals, Medimmune, and Chugai Pharma USA; received research support from Alexion Pharmaceuticals, Guthy Jackson Charitable Foundation, S.J. Pittock, and Mayo Clinic; and has a financial interest in patents that relate to functional AQP4/NMO-IgG assays and NMO-IgG as a cancer marker. Go to Neurology.org/nn for full disclosure forms.

Received November 25, 2015. Accepted in final form March 15, 2016.

\section{REFERENCES}

1. Pittock SJ, Lucchinetti CF. Neuromyelitis optica and the evolving spectrum of autoimmune aquaporin- 4 channelopathies: a decade later. Ann NY Acad Sci Epub 2015 Jun 10 .

2. Wingerchuk DM, Lennon VA, Pittock SJ, Lucchinetti CF, Weinshenker BG. Revised diagnostic criteria for neuromyelitis optica. Neurology 2006;66:1485-1489.

3. Wingerchuk DM, Lennon VA, Lucchinetti CF, Pittock SJ, Weinshenker BG. The spectrum of neuromyelitis optica. Lancet Neurol 2007;6:805-815.

4. Jarius S, Frederikson J, Waters P, et al. Frequency and prognostic impact of antibodies to aquaporin- 4 in patients with optic neuritis. J Neurol Sci 2010;298:158-162.

5. Fryer JP, Lennon VA, Pittock SJ, et al. AQP4 autoantibody assay performance in clinical laboratory service. Neurol Neuroimmunol Neuroinflamm 2014;1:e11. doi: 10.1212/NXI.0000000000000011.

6. Waters PJ, McKeon A, Leite MI, et al. Serologic diagnosis of NMO: a multicenter comparison of aquaporin-4-IgG assays. Neurology 2012;78:665-671; discussion 669.

7. Dujmovic I, Mader S, Schanda K, et al. Temporal dynamics of cerebrospinal fluid anti-aquaporin- 4 antibodies in patients with neuromyelitis optica spectrum disorders. J Neuroimmunol 2011;234:124-130.

8. Jarius S, Franciotta D, Paul F, et al. Cerebrospinal fluid antibodies to aquaporin- 4 in neuromyelitis optica and related disorders: frequency, origin, and diagnostic relevance. J Neuroinflammation 2010;7:52.

9. Sato DK, Callegaro D, de Haidar Jorge FM, et al. Cerebrospinal fluid aquaporin-4 antibody levels in neuromyelitis optica attacks. Ann Neurol 2014;76:305-309.

10. Takahashi T, Fujihara K, Nakashima I, et al. Antiaquaporin- 4 antibody is involved in the pathogenesis of NMO: a study on antibody titre. Brain 2007;130: 1235-1243.

11. McKeon A, Pittock SJ, Lennon VA. CSF complements serum for evaluating paraneoplastic antibodies and NMO-IgG. Neurology 2011;76:1108-1110.

12. Reiber H, Lange P. Quantification of virus-specific antibodies in cerebrospinal fluid and serum: sensitive and specific detection of antibody synthesis in brain. Clin Chem 1991;37:1153-1160.

13. Gresa-Arribas N, Titulaer MJ, Torrents A, et al. Antibody titres at diagnosis and during follow-up of anti-NMDA receptor encephalitis: a retrospective study. Lancet Neurol 2014;13:167-177. 


\title{
Neurology \\ Neuroimmunology \& Neuroinflammation
}

\author{
Clinical utility of testing AQP4-IgG in CSF: Guidance for physicians \\ Masoud Majed, James P. Fryer, Andrew McKeon, et al. \\ Neurol Neuroimmunol Neuroinflamm 2016;3; \\ DOI 10.1212/NXI.0000000000000231
}

This information is current as of April 20, 2016

\section{Updated Information \& Services}

References

Citations

Subspecialty Collections

Permissions \& Licensing

Reprints including high resolution figures, can be found at: http://nn.neurology.org/content/3/3/e231.full.html

This article cites 12 articles, 1 of which you can access for free at: http://nn.neurology.org/content/3/3/e231.full.html\#\#ref-list-1

This article has been cited by 6 HighWire-hosted articles: http://nn.neurology.org/content/3/3/e231.full.html\#\#otherarticles

This article, along with others on similar topics, appears in the following collection(s):

All Practice Management

http://nn.neurology.org//cgi/collection/all_practice_management Autoimmune diseases

http://nn.neurology.org//cgi/collection/autoimmune_diseases Cerebrospinal Fluid

http://nn.neurology.org//cgi/collection/cerebrospinal_fluid

Devic's syndrome

http://nn.neurology.org//cgi/collection/devics_syndrome

Information about reproducing this article in parts (figures,tables) or in its entirety can be found online at:

http://nn.neurology.org/misc/about.xhtml\#permissions

Information about ordering reprints can be found online: http://nn.neurology.org/misc/addir.xhtml\#reprintsus

Neurol Neuroimmunol Neuroinflamm is an official journal of the American Academy of Neurology.

Published since April 2014, it is an open-access, online-only, continuous publication journal. Copyright $\odot$ 2016 American Academy of Neurology. All rights reserved. Online ISSN: 2332-7812.

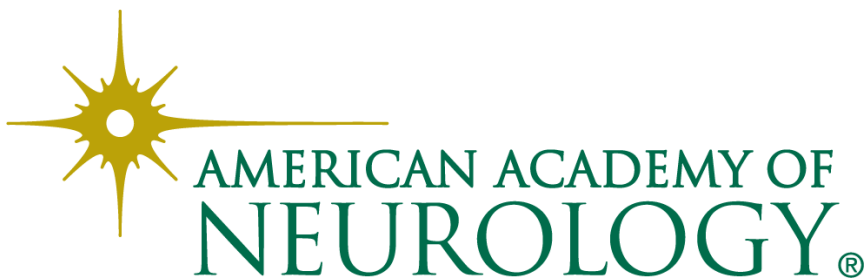

